\title{
DARI SEJARAH MENUJU PENGEMBANGAN PARIWISATA BERKELANJUTAN : STUDI KASUS KAMPUNG WISATA PANCER
}

\author{
Irwan Tamrin \\ Magister Pariwisata Berkelanjutan, Universitas Padjadjaran \\ E-mail: irwantamrin.wsi@gmail.com \\ Rusdin Tahir \\ Magister Pariwisata Berkelanjutan, Universitas Padjadjaran \\ E-mail: rusdin@unpad.ac.id \\ M. Liga Suryadana \\ Sekolah Tinggi Pariwisata, Bandung \\ E-mail: mligasuryada@gmail.com \\ Arfah Sahabudin \\ Magister Pariwisata Berkelanjutan, Universitas Padjadjaran \\ E-mail: arfah18001@mail.unpad.ac.id
}

\begin{abstract}
Indonesia has made tourism as the leading sector in economy. This has prompted many regions to compete to develop their tourism potential, including Kota Serang Banten by launching Kampung Wisata Pancer. Kampung Pancer is closely related to the history of the Karangantu Harbour area, which was an international port during the Banten Kingdom era. Not many studies have discussed about the development of sustainable tourism in the Banten region. This article aims to show the progress of tourism in Banten today. Its development has allowed tourism to stand on its own feet. This study is based on an overview of secondary sources and observations and personal interviews with several informants and tourism experts. The results of this study showed that the tourism development efforts in Kampung Wisata Pancer are not in accordance with the concept of sustainable tourism development.
\end{abstract}

Keywords: Tourism Village, Community Based Tourism, Sustainable Tourism Development

\section{Pendahuluan}

Pariwisata di Indonesia saat ini berkembang semakin pesat. Perkembangan sektor pariwisata terbukti menjanjikan dan memberikan manfaat kepada banyak 
pihak baik masyarakat, swasta maupun pemerintah. Pariwisata dianggap sebagai sektor yang menguntungkan sebagai sumber devisa sehingga didorong untuk menjadi leading sector. Tercatat negara-negara di Asia seperti Thailand, Malaysia dan Singapura telah menunjukkan perkembangan pertumbuhan ekonominya dengan menjadikan pariwisata sebagai sector unggulan. Berdasarkan data United Nation World Tourism Organization (UNWTO), sebanyak 129,2 juta jiwa wisatawan bepergian ke negara-negara ASEAN, namun hanya 15,8 juta jiwa yang datang mengunjungi Indonesia (UNWTO Tourism Highlights: 2018 Edition I UNWTO, 2018). Dari data tersebut terlihat bahwa Indonesia memiliki potensi yang besar untuk bisa mendatangkan lebih banyak lagi wisatawan manca negara terlebih masih banyak destinasi pariwisata yang belum dikembangkan secara optimal.

Pemerintahan Joko Widodo menyadari betul akan hal ini. Oleh sebab itu, Pada tahun 2019 Pemerintah menargetkan sektor pariwisata sebagai sektor yang dapat memberikan kontribusi terhadap PDB (Pendapatan Devisa Bruto) nasional sebesar 15 \% (KemenkeuRI, 2019). Dari target baru tersebut pengembangan sector pariwisata pada suatu Kawasan atau destinasi pariwisata diharapkan dapat mendongkrak perekonomian nasional karena pada dasarnya destinasi pariwisata berperan sebagai tempat bertemunya permintaan dan penawaran (Mrsic et al., 2020).

Menurut Cooper (2005), terdapat empat komponen dalam pengembangan pariwisata yang harus terpenuhi dalam sebuah destinasi pariwisata yaitu Attractions, Accessibilities, Amenities dan Ancillary Services. Yang dimaksud dengan Attractions adalah keindahan alam, kebudayaan masyarakat setempat serta aktivitas wisata buatan yang merupakan daya tarik yang ditawarkan oleh sebuah destinasi. Sementara akses transportasi yang tersedia menuju, dari dan di dalam kawasan pariwisata seperti rute penerbangan, jalur kereta, transportasi darat dan laut menjadi bagian dari Accessibilities. Dan Amenities adalah fasilitas atau bagian dari akomodasi yang terdapat di destinasi pariwisata seperti penginapan dalam bentuk hotel, 
homestay dan lain-lain serta sarana pendukung lainnya seperti rumah makan, tempat penjualan souvenir, pusat hiburan, fasilitas kesehatan, listrik, air bersih, dan sarana pengolahan sampah atau limbah. Sedangkan Ancillary services lebih mengarah kepada pelayanan tambahan seperti adanya organisasi kepariwisataan yang bertujuan untuk mengakomodir kebutuhan wisatawan contohnya asosiasi biro perjalanan wisata, asosiasi perhotelan, asosiasi pemandu wisata, dan lain-lain.

Pengembangan pariwisata harus dilakukan dengan perencanaan yang matang dan dengan upaya-upaya peningkatan kualitas SDM yang berkualitas dunia (Nirwandar, 2011). Pariwisata tidak saja memberi manfaat di masa sekarang tapi juga di masa yang akan datang agar dapat berkelanjutan dan mengandung unsur pelestarian. Sehingga adanya konsep pariwisata yang berkelanjutan (Sustainable Tourism) adalah untuk mengurangi dampak negatif dari mass tourism atau pariwista yang bersifat masal. Dari sudut pandang pariwisata, keberlanjutan pembangunan seperti yang dikemukakan oleh Elkington (1994) dapat didefinisikan sebagai keseimbangan antara tiga pilar yaitu perlindungan lingkungan, kesetaraan sosial dan pertumbuhan ekonomi atau lebih dengan konsep 3P yaitu planet, people $\mathcal{E}$ profit (Böcker \& Meelen, 2017; Camisón, 2020; Postma et al., 2017). Setiap orang harus merasa bertanggung jawab terhadap wilayahnya yang akan dijadikan daerah tujuan wisata agar senantiasa terjaga dan dapat dinikmati.

Pada awalnya konsep sustainable tourism diambil dari konsep pembangunan berkelanjutan atau sustainable development yang diperkenalkan pertama kali oleh WCED World Commission on Environment and Development (WCED) pada tahun 1987. Kemudian The World Tourism Organization (UNWTO) mengadopsi konsep keberlanjutan tersebut dengan mendefinisikan pariwisata berkelanjutan sebagai suatu bentuk pariwisata yang memperhatikan kelestarian alam atau lingkungan, nilai-nilai sosial budaya serta dampak kesejahteraan pada masyarakat. Suatu bentuk pariwisata dimana diantara kedua belah pihak yaitu pihak tuan rumah (host) dan 
tamu (guest) bisa saling berbagi tentang pengalaman baru dan menikmati keramahtamahan di antara mereka (Farmaki \& Stergiou, 2019).

Namun didalam pelaksanaannya tentu saja terdapat tantangan dalam rangka upaya menuju konsep pariwisata yang berkelanjutan yaitu keberlangsungan lingkungan, sosial budaya dan juga ekonomi (Goeldner, C. R., \& Ritchie, 2009). Senada dengan hal tersebut, menurut Pan et al. (2018), ada tiga pilar yang harus terpenuhi didalam pembangunan pariwisata berkelanjutan yaitu keberlanjutan dalam aspek lingkungan, keberlanjutan dalam aspek sosial budaya dan juga keberlanjutan dalam hal ekonomi.

Berkelanjutan pada aspek lingkungan dapat dilakukan dengan cara memanfaatkan sumber daya yang ada dilingkungan secara optimal melakukan pembatasan terhadap sumber daya itu sendiri. Menjaga kelestarian dan eksistensi warisan alam serta keanekaragaman hayati dan juga menjaga proses ekologi pada sebuah daya tarik wisata. Sementara berkelanjutan pada aspek ekonomi ditunjukkan dengan adanya kegiatan pariwisata yang mampu mengurangi tingkat kemiskinan, menciptakan kesempatan kerja serta baru yang pada akhirnya mendorong pertumbuhan ekonomi pada daerah tersebut. Sedangkan berkelanjutan pada aspek sosial budaya ditunjukkan dengan membuat kesepakatan dalam bentuk aturan dan ketentuan Bersama yang bertujuan untuk menjaga kemurnian sosial budaya yang dimiliki masyarakat, melestarikan adat istiadat serta warisan budaya, serta meningkatkan pemahaman dan nilai toleransi antar budaya yang ada di masyarakat setempat. Menurut Lee \& King (2019) kriteria untuk pengembangan pariwisata yang berkelanjutan harus selalu melibatkan masyarakat lokal dan mampu memberikan manfaat kepada masyarakat setempat dengan tidak merusak nilai-nilai sosial budaya yang ad apada masyarakat tersebut. Untuk itu diperlukan strategi yang disesuaikan dengan karakter daerah masing-masing. 
Salah satu strategi yang sering digunakan dalam Pengembangan pariwisata berkelanjutan adalah pengembangan pariwisata yang menggunakan prinsip pemberdayaan masyarakat (Community Based Tourism). Dalam perkembangan teori pembangunan kepariwisataan secara konvensional (growth oriented model), kerangka dasar community based tourism merupakan gagasan yang dianggap penting dan kritis yang sering kali mendapatkan kritik dan saran karena tidak memperhatikan hak dan terkadang meminggirkan peran masyarakat lokal dari kegiatan kepariwisataan yang ada di suatu destinasi pariwisata (Rahayu et al., 2015).

Pondasi dari sustainable tourism development atau pembangunan pariwisata berkelanjutan adalah adanya konsep pariwisata berbasis pemberdayaan masyarakat atau yang lazim dikenal dengan istilah community-based tourism. Yang harus menjadi suatu keniscayaan adalah bahwa masyarakat bukan lagi bertidak sebagai objek pembangunan akan tetapi berperan sebagai penentu dari pembangunan itu sendiri (Ardika, 2005). Upaya mempersiapkan masyarakat dan wisatawan atau pengunjung agar dapat berinteraksi secara spontan dengan memberikan pemahaman dan pengetahuan tentang wawasan lingkungan dan kebudayaan setempat perlu terus dilakukan. Karena sejatinya pariwisata berbasis pemberdayaan masyarakat berawal dari strategi pengembangan dan partisipasi masyarakat local yang menjadikan pariwisata sebagai alat untuk mengkontrol pertumbuhan pariwisata yang dapat memberikan manfaat secara langsung kepada masyarakat serta memiliki karakter pemberdayaan (Djou et al., 2017).

Untuk menanamkan rasa bangga masyarakat lokal terhadap kebudayaan yang dimilikinya, penekanan pada tata cara hidup masyarakat tradisional (live like locals) dan merupakan bagian penting yang harus selalu dipertimbangkan dalam pengembangan pariwisata yang dapat dikemas dalam bentuk desa wisata atau kampung wisata. Ditambah dengan proses pengendalian sebagai salah satu aspek 
didalam community based tourism yang juga menentukan pemberdayaan dan kemandirian dari masyarakat itu sendiri (Rakhman et al., 2014).

Kota Serang di Provinsi Banten adalah salah satu daerah yang ikut melakukan pengembangan pariwisata dengan konsep community-based tourism dengan salah satunya mendeklarasikan berdirinya Kampung Wisata Pancer pada tahun 2018. Kampung Pancer adalah sebuah kampung yang berada persis di daerah Pelabuhan Karangantu yang memiliki jarak kurang lebih 11 kilometer dari pusat Kota Serang.

Menurut catatan sejarah, pada awal abad ke-15 kampung tersebut dahulunya adalah sebuah bandar pelabuhan yang memiliki peranan penting dalam lalulintas perdagangan internasional. Kala itu, Banten dijadikan tempat transit bagi jalur perdagangan antar negara. Pelabuhan Karangantu dahulunya adalah pelabuhan besar tertua di Pulau Jawa yang digunakan sebagai pintu gerbang perdagangan internasional untuk wilayah Nusantara (Indonesia). Dari pelabuhan yang berada di pesisir utara Banten inilah oleh para saudagar dan pedagang-pedagang besar dikala itu yang berlayar memasuki wilayah Nusantara Karangantu dijadikan sebagai pintu keluar masuk. Tercatat beberapa Kapal-kapal asing yang pernah singgah di pelabuhan ini diantaranya berasal dari negara Portugis, Inggris, Belanda, Arab, Persia, Gujarat, dan Cina (Tjandrasasmita, U., Ambary, H. M., \& Michrob, 1999).

Bukti-bukti kebesaran Pelabuhan Karangantu tidak hanya tercatat di dalam buku. Beberapa bukti lain juga menunjukkan bahwa terdapat barang-barang yang pernah diperjualbelikan dan dijadikan komoditas pada masa kejayaan Banten Lama yang dapat dilihat di Museum Situs Kepurbakalaan Kawasan Kesultanan Banten. Di museum ini, tersimpan dengan rapi beberapa benda peninggalan masa lalu seperti porselen dan guci dari Belanda, China dan Jepang sebagai upaya pelestarian kawasan bersejarah ini.

Kekuatan sejarah yang dimiliki Pelabuhan Karangantu adalah sebuah asset bagi masyarakat setempat. Keinginan yang kuat dari masyarakat yang tergabung 
dalam sebuah Kelompok Sadar Wisata (Pokdarwis) Kiamuk untuk memahsyurkan kembali dan merubah Kawasan Pelabuhan Karangantu yang tadinya kumuh menjadi kawasan wisata didukung pemerintah setempat melalui Dinas Pariiwisata Kepemudaan dan Olahraga (Disparpora) Kota Serang melalui sosialisasi sadar wisata dan pariwisata berbasis masyarakat; maka terceteuslah Kampung Wisata Pancer yang diresmikan oleh Pemerintah Kota Serang 2018 lalu.

Kampung Wisata Pancer kemudian berubah dalam waktu yang relative singkat menjadi destinasi wisata bahari populer dan menjadi unggulan di Kota Serang. Karena letaknya yang strategis, kini pemerintah Kota Serang telah menetapkan Pelabuhan Karangantu dan Kampung Pancer sebagai 'destinasi pariwisata baharinya Kota Serang". Dari pelabuhan ini wisatawan juga dapat mengunjungi pulau-pulau yang berada tidak jauh dari daratan seperti Pulau Burung, Pulau Lima dan Pulau Tunda. Hal ini tentu saja memberikan manfaat ekonomi bagi masyarakat sekitar Pelabuhan Karangantu dan Kampung Wisata Pancer. Keterlibatan masyarakat dalam upaya pengelolaan Kampung Wisata Pancer melalui Pokdarwis Kiamuk inilah yang menjadi suatu hal yang sangat menarik untuk dikaji lebih dalam.

Permasalahan yang diangkat dalam penelitian ini adalah apakah upaya pengembangan pariwisata di Kampung Wisata Pancer sudah sesuai dengan konsep pembangunan pariwisata berkelanjutan. Penulis berharap penelitian ini dapat membantu pengembangan pariwisata yang berkelanjutan di Kampung Wisata Pancer sehingga berguna dalam memberikan solusi yang dapat direkomendasikan bagi pihak pengelola dan pemerintah sebagai pihak pembuat regulasi. Melalui penelitian ini diharapkan juga dapat memberikan kontribusi bagi pengembangan ilmu pengetahuan serta manfaat secara akademis khususnya terkait dengan pengembangan pariwisata berkelanjutan terkait dan peningkatan kesejahteraan masyarakat di destinasi pariwisata. 


\section{Metode Penelitian}

Penelitian dilakukan dengan menggunakan metode penelitian deskriptif dengan pendekatan kualitatif. Jenis data yang dikumpulkan adalah data primer dan sekunder. Teknik pengumpulan data dilakukan melalui observasi (pengamatan), wawancara langsung (interview), dan studi dokumen (Emzir, 2012). Peneliti melakukan observasi terhadap kegiatan yang dilakukan masyarakat di Kampung Wisata, sarana dan prasarana pariwisata yang telah ada maupun baru akan dikembangkan di daerah Kampung Wisata Pancer dan sekitarnya dalam rangka menunjang pengembangan pariwisata berkelanjutan.

Saat wawancara peneliti berusaha menggali pendapat dari Pokdarwis Kiamuk dan kelompok masyarakat sebagai bagian dari pengembangan dan pengelolalaan. Untuk mengetahui aspek ekonomi yang dibangun, aspek pelestarian dan sadar wisata. Studi literatur dan dokumen lainnya juga digunakan oleh peneliti untuk dapat memberikan pemahaman dari hasil wawancara dan observasi yang dilakukan yaitu berupa dokumen tentang rencana pengembangan pariwisata Kota Serang, buku literatur sejarah, serta dokumen dari Pokdarwis Kiamuk.

Informasi yang didapat terkait prinsip serta strategi pengembangan destinasi pariwisata di Kampung Wisata Pancer kemudian dinilai melalui empat (4) komponen pengembangan destinasi pariwisata yaitu attractions, accessibilities, amenities, dan ancillary services kemudian dipadukan dengan Sustainable Tourism Concept yang dikeluarkan oleh UNWTO dengan 3 pilarnya yaitu Ecological Sustainability, Social And Cultural Sustainability, dan Economic Sustainability (UNWTO, 2013). Dengan menggunakan konsep dan komponen tersebut maka akan didapat gambaran tentang praktek pengembangan pariwisata di Kampung Wisata Pancer apakah sudah sesuai dengan konsep pembangunan pariwisata berkelanjutan. 


\section{Hasil dan Pembahasan}

\section{Pariwisata di Kampung Pancer}

Berlokasi di kawasan Pelabuhan Karangantu, Kecamatan Kasemen - Serang, Kampung Wisata Pancer memiliki potensi untuk berkembang menjadi salah satu kampung wisata dengan sejarah dan kearifan lokal. Hal ini terlihat dari perkampungan nelayan yang masih menerapkan nilai-nilai kearifan local serta jejak historis. Ditambah dengan kekayaan alam berupa lahan mangrove yang berhadapan langsung dengan bibir pantai menjadi pelengkap dari salah satu rintisan kampung wisata yang berlokasi tidak jauh dari Kawasan Kesultanan Banten, sehingga memberikan nilai tambah tersendiri bagi kampung wisata ini.

Karena berada tidak jauh dari pusat kota Serang, komponen pariwisata ditempat ini sudah terbilang lengkap. Seluruh sarana dan prasarana Pariwisata di Kawasan Pelabuhan Karangantu dan Kampung Wisata Pancer mulai di integrasikan dengan adanya revitalisasi Kawasan Banten Lama yang baru-baru ini dirubah penamaannya oleh Pemerintah Provinsi Banten menjadi Kawasan Kesultanan Banten. Terdapat beberapa temuan yang menarik untuk dibahas berdasarkan hasil observasi, studi dokumentasi serta wawancara yang dilakukan terhadap beberapa anggota Pokdariwis Kiamuk Kampung Wisata Pancer.

Tabel 1. Daya Tarik Wisata di Kampung Wisata Pancer (diresmikan Walikota Serang 2018)

\begin{tabular}{lll}
\hline \multicolumn{1}{l}{ Daya Tarik Alam } & \multicolumn{1}{c}{ Daya Tarik Budaya } & Daya Tarik Buatan \\
\hline 1. Pelabuhan & 1. Yalil & 1. Jembatan Cinta \\
Karangantu & 2. Marhaban & Mangrove \\
2. Hutan Mangrove & 3. Panjang Maulud & 2. Wisata Mangrove \\
Pancer & 4. Nadran (Pesta Laut) & Pancer \\
3. Teluk Banten & 5. Festival Masyarakat & 3. Spot Selfie \\
4. Hutan Mangrove STP & Pesisir & 4. Wisata Mancing \\
& 6. Komplek Masjid & 5. Museum Purbakala \\
& Agung & 6. Wisata Bahari \\
\hline
\end{tabular}


7. Keraton Surosowan

8. Benteng Spelwijk

9. Vihara Avalokitesvara

10. Masjid Pecinan

11. Meriam Kiamuk

12. Makam TB. Buang

13. Komplek Pemakaman Kasultanan Banten

14. Makam Pangeran Aliyuddin
7. Wisata Edukasi Daur Ulang Plastik

8. Wisata Kuliner Laut

9. Pemecah ombak

10. Dermaga Kapal

Sumber: Forum Pokdarwis Kota Serang (2020)

\section{Attraction}

Komponen atraksi wisata yang ditawarkan oleh Kampung Wisata Pancer adalah :

a. Wisata Alam

Kegiatan wisata bahari yang dapat dilakukan oleh wisatawan diantaranya adalah hoping island ke pulau-pulau sekitar yang jaraknya dekat dari Pelabuhan Karangantu diantaranya Pulau Burung, Pulau Tiga, Pulau Lima dan Pulau Tunda. Kegiatan menikmati sunrise atau sunset serta sekedar menikmati pantai dengan barbeque bisa dilakukan di Pulau Tiga dan Pulau Lima. Lokasi snorkelling dan diving bisa dilakukan di Pulau Tunda. Namun Pulau Tunda menjadi bagian dari Kabupaten Serang, Kampung Wisata Pancer yang berada di Kawasan Pelabuhan Karangantu hanya menjadi tempat transit untuk menuju pulau tersebut. Untuk kegiatan memancing sebagian besar bisa di lakukan di sekitar pantai Kampung Wisata Pancer.

Aktivitas wisata alam yang lain yang juga bisa dilakukan wisatawan antara lain trekking hutan mangrove, menyusuri Jembatan Cinta untuk melihat view laut ketika sunset yang lokasinya berada di hutan mangrove sekitar wilayah pantai 
Kampung Pancer hingga menuju Benteng Spelwijck. Jembatan Cinta ini baru saja di renovasi dengan bantuan dari Dinas Pariwisata Provinsi Banten. Namun penggunaan fasilitas wisata Jembatan Cinta ini tidak sepenuhnya bisa di akses dengan mudah karena akses masuk ke Kawasan tersebut merupakan wilyah Pos Pantau TNI AL sehingga terdapat konflik kepentingan untuk pengelolaan kawasan tersebut.

b. Wisata Budaya.

Kegiatan wisata budaya yang bisa dilakukan di Kampung Wisata Pancer umumnya berkaitan dengan sejarah perkembangan Banten karena posisinya yang berada di Kawasan Pelabuhan Karangantu yang dulunya merupakan pusat perdagangan. Terdapat beberapa etnis yang singgah dan akhirnya menetap kemudian membawa adat dan budayanya masing-masing. Penduduk dari berbagai etnis ini yang merupakan mayoritas diantaranya adalah Sunda (Cirebon), Jawa dan para pelaut Bugis yang terasimilasi sehingga menjadikan keragaman budaya ini sebagai daya tarik tersendiri di Kampung Pancer. Rampak Bedug, Debus, Silat, Ketimpringan dan Perkawinan Suku Bugis adalah beberapa bentuk budaya yang bisa disaksikan sebagai atraksi wisata di Kampung Pancer.

\section{c. Wisata Buatan.}

Kampung Wisata Pancer sudah menyiapkan beberapa paket wisata buatan dalam bentuk wisata edukasi sebagai produk pariwisata kampung ini. Kegiatan wisata edukasi yang bisa dilakukan di Kampung Wisata Pancer diantaranya adalah belajar menganyam jaring, pengalaman sehari menjadi nelayan, kegiatan memanen kerang serta aktivitas daur ulang sampah plastik untuk dirubah menjadi kreasi pajangan dan hiasan. Kampung Wisata Pancer juga menggabungkan kegiatan ini dengan paket wisata edukasi ke Kawasan Kesultanan Banten diantaranya mengunjungi Keraton Kaibonan, Masjid Agung Banten, Keraton Surosowan, Benteng Spelwijck dan mengunjungi Vihara Avalokitesvara dengan konsep walking tour. 


\section{Accessibilities}

Sebagai Buffer Zone dari Kawasan Kesultanan Banten, akses menuju Kampung Wisata Pancer dari pusat Kota Serang tentu saja menjadi perhatian Pemerintah Kota dan Provinsi. Terdapat kendaraan umum yang keluar masuk Kawasan Kampung Wisata Pancer mulai dari pagi hingga dini hari.

Akses kendaraan umum dari dan menuju kota serang pun terbuka selama 24 jam melalui terminal kota serang. Tidak jauh dari Kampung Pancer juga terdapat stasiun kereta Karangantu sehingga jalur kereta bisa dijadikan sebagai alternatif menuju dan dari Kampung Wisata Pancer. Kendati sempat dikeluhkan karena akses jalan yang parah di jalan utama Kampung Pancer, kini akses jalan tersebut sudah dilakukan proses betonisasi sebagai upaya Pemerintah Kota Serang dalam menambah kenyamanan wisatawan di satu-satunya tempat wisata pantai di Kota Serang tersebut.

\section{Amenities}

Di Kampung Wisata Pancer terdapat 11 rumah yang dijadikan Homestay sebagai alternative penginapan. Karena mengedepankan konsep pemberdayaaan masyarakat, homestay dijadikan pilihan yang tepat bagi wisatawan untuk bisa merasakan kehidupan masyarakat nelayan di Kampung Wisata Pancer. Selain itu terdapat juga toko, warung, kios dan rumah makan sebagai sarana pelengkap di tempat ini. 


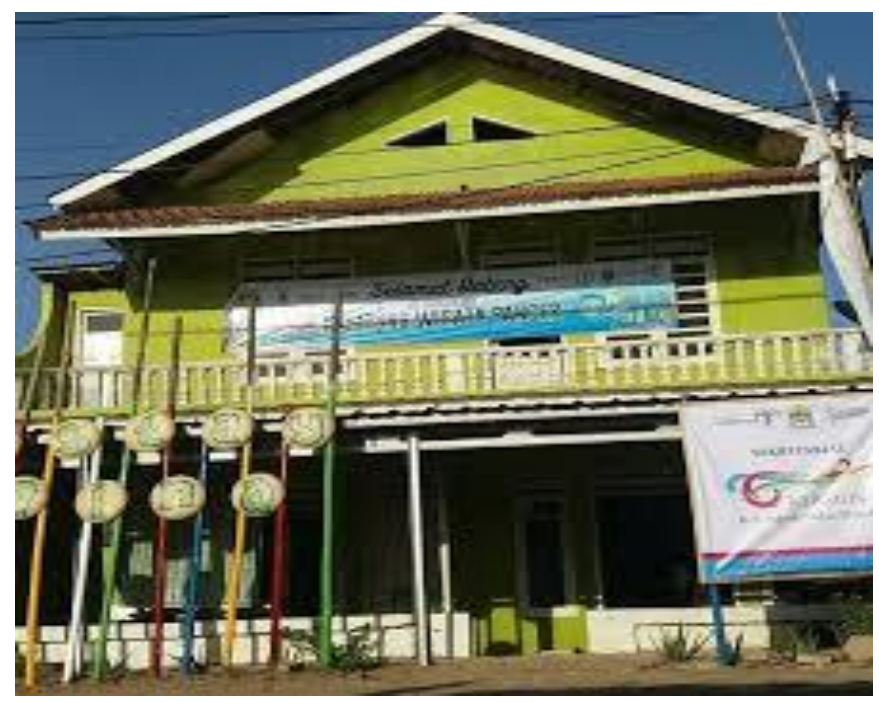

Gambar 1. salah satu Homestay di Kampung Wisata Pancer Sumber : Pokdarwis Kiamuk

Untuk fasilitas umum sebagai pendukung pariwisata di Kampung Wisata Pancer diantaranya adalah 4 buah sarana peribadatan berupa bangunan masjid, 1 unit sarana Kesehatan (Puskesmas), 2 pasar sebagai sarana perekonomian serta 2 buah Bank yang dilengkapi dengan 3 anjungan ATM. Adapun prasarana umum yang berada di Kampung Wisata Pancer sebagai pendukung pariwisata yaitu :

1. Jaringan kelistrikan 24 jam. Saat ini seluruh warga di Kampung Pancer sudah menikmati jaringan listrik dari PLN.

2. Jaringan telekomunikasi nirkabel dan koneksi internet seluruh provider telekomunikasi juga bisa di akses di tempat ini.

3. Sebagai Kawasan tepi pantai yang memiliki kondisi air yang payau, sayangnya fasilitas air bersih yang sudah ada kadang tidak berfungsi dan belum menjangkau semua rumah di daerah ini sehingga warga harus membeli dari penampung. Untuk air minum, warga lebih memilih untuk membeli air isi ulang. 
4. Belum terdapat sarana pengelolaan sampah akhir di Kampung Pancer. Isu kebersihan dan sampah plastik menjadi hal yang selalu dikeluhkan pengunjung.

\section{Ancillary Services}

Untuk menunjang kegiatan kepariwisataan di Kampung Wisata Pancer, dibutuhkan organisasi atau perkumpulan yang berfungsi sebagai pelayanan wisatawan. Terdapat beberapa organisasi yaitu :

1. Pokdarwis Kiamuk, merupakan kelembagaan yang anggotanya terdiri dari para pelaku kepariwisataan yang memiliki kepedulian terhadap pariwisata di Kampung Pancer.

2. Himpunan Pramuwisata Indonesia, Sebagian besar anggota Pokdarwis Kiamuk juga terdaftar sebagai anggota HPI yang merupakan organisasi Pemandu Wisata.

3. Paguyuban Perahu Penyeberangan Karangantu, adalah wadah silaturahmi para pengusaha penyewaan kapal wisata di Karangantu.

\section{Upaya menuju Pariwisata Berkelanjutan}

Sejatinya pembangunan pariwisata yang berkelanjutan diharapkan dapat menjamin keberlangsungan atau keberadaan sumber daya alam, kearifan lokal dan ekonomi. Pariwisata berkelanjutan adalah pengembangan pariwisata yang memperhatikan aspek sosial budaya tanpa merusak lingkungan sehingga bisa memberikan manfaat ekonomi kepada masyarakat local secara jangka panjang. UNWTO (2013) menegaskan bahwa pembangunan berkelanjutan haruslah mengandung tiga unsur yang berkelangsungan agar dapat dinikmati oleh generasi yang akan datang yaitu : 


\section{Ecological Sustainability}

Keseimbangan lingkungan sering menjadi permasalahan bagi kampung wisata karena kampung wisata umumnya menyajikan kehidupan masyarakat sehari-hari serta keindahan alam sebagai atraksi utama. Keindahan alam akan tetap terjaga apabila masyarakat memiliki kesadaran terhadap potensi wisata yang dimiliki daerahnya. Seperti halnya Kampung Wisata Pancer yang berada di Kawasan Pelabuhan Karangantu yang dulunya memiliki kejayaan kini kawasan ini telah menjelma menjadi perkampungan nelayan yang terkesan kumuh. Sampah berserakan dimana-mana dan lumpur yang berasal dari dasar sungai terlihat menumpuk di tepi dermaga dan jalan menuju Pelabuhan Karangantu.

Sebagai perkampungan pesisir yang padat penduduknya, pengelolaan sampah adalah salah satu masalah yang dimiliki oleh Kampung Wisata Pancer. Sampah-sampah ini berasal dari limbah rumah tangga dan limbah yang dihasilkan dari kegiatan wisata di sekitar Kampung Wisata Pancer (Sahabudin, A., Rusdin, T., \& Hadian, 2020). Kondisi ini tentunya harus bisa ditangani oleh pengelola apabila ingin menjadikan Kampung Wisata Pancer sebagai destinasi pariwisata yang diminati oleh wisatawan.

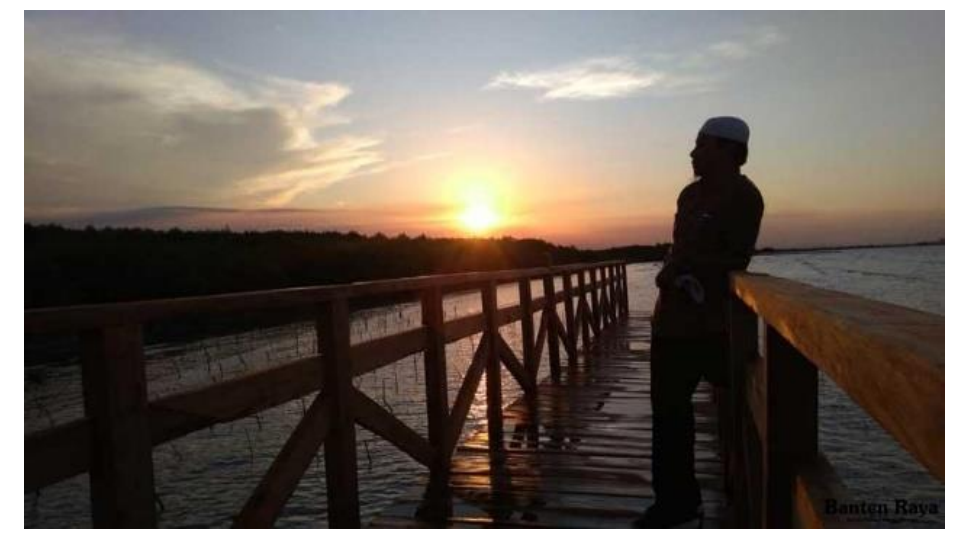

Gambar 2. Jembatan pandang di Kampung Wisata Pancer Sumber : Pokdarwis Kiamuk 
Permasalahan sampah ini disebabkan Kampung Pancer tepat berada di bantaran sungai Cibanten. Sampah bawaan yang berujung di muara sungai menjadi masalah serius yang harus ditangani oleh Kampung Wisata Pancer. Namun keberadaan Pokdarwis Kiamuk perlahan-lahan mulai bisa mengatasi permasalahan tersebut. Meskipun belum memiliki tempat pembuangan akhir, Pokdarwis bersama warga masyarakat mulai bahu membahu mengadakan aksi kebersihan secara rutin dan membuat pengelolaan sampah untuk dibawa ke tempat pembuangan akhir diluar wilayah Kampung Pancer.

\section{Social and Cultural Sustainability}

Keberlanjutan sosial dan budaya masyarakat adalah aspek yang juga patut dijadikan perhatian karena memiliki kaitan erat dengan kearifal lokal masyarakat setempat. Aspek sosial dan budaya di destinasi merupakan sumber daya pariwisata yang penting yang tidak hanya dapat memberikan manfaat kepada industri pariwisata namun juga bisa menjadi peluang bagi asyarakat lokal untuk dapat mengambil manfaat dari pariwisata.

Salah satu upaya yang dilakukan oleh Pokdarwis sebagai pengelola Kampung Wisata Pancer adalah dengan menyisipkan kegiatan tari-tarian dan pertunjukan seni budaya yang dikemas dalam bentuk paket wisata edukasi yang ditawarkan kepada wisatawan. Upaya lain yang juga dilakukan pengelola untuk menjaga keberlanjutan sosial budaya di Kampung Wisata Pancer adalah dengan mengadakan kegiatan Festival Pesisir. Dalam kegiatan ini ditampilkan berbagai seni pertunjukan seperti silat bandrong, nadran laut, tarian walijamaliah dan teatrikal tari pelabuhan karangantu. Pokdarwis sebagai pengelola terus berupaya melestarikan budaya local agar tidak tergerus modernisasi dan globalisasi. 


\section{Economic Sustainability}

Keberlanjutan ekonomi adalah aspek yang memiliki kaitan dengan pendapatan atau perekonomian yang dinikmati langsung oleh masyarakat Kampung Wisata Pancer dengan adanya pariwisata. Perekonomian yang berkelanjutan menjadi tantangan bagi pengelola mengingat belum banyak masyarakat lokal yang terlibat dalam bidang pariwisata. Belum lagi angka pengangguran dan jumlah penderita gizi buruk yang cukup tinggi di daerah ini tentu menuntut keseriusan pengelola dan aparat pemerintah setempat untuk dapat menciptakan perekonomian terutama melalui pariwisata di Kampung Wisata ini.

Minimnya pendanaan untuk pengelolaan Kampung Wisata juga menjadi tantangan dalam pengembangan pariwisata di Kampung ini. Pengelola telah berupaya untuk menciptakan unit-unit usaha dimana pengelolaannya melibatkan masyarakat lokal. Pihak swasta dan pemerintah melalui dinas terkait juga telah diupayakan untuk berkontribusi dalam peningkatan kapasitas. Salah satunya melalui pendampingan di Kampung Wisata Pancer agar kampung ini bisa menunjukkan performa terbaiknya.

Beragam prestasi yang diraih oleh Pokdarwis Kiamuk dari Kampung Wisata Pancer. Predikat pemenang Juara 1 Lomba Pokdarwis se-Provinsi Banten telah menarik perhatian beberapa pihak. Ditambah dengan apresiasi sebagai Juara 3 Pokdarwis terbaik se-Indonesia dari Kementrian Pariwisata RI dalam rangkaian acara Indonesia Sustainable Tourism Award tahun 2019 menambah keyakinan berbagai pihak untuk memberikan bantuan sebagai bentuk kepedulian terhadap masyarakat Kampung Pancer. Diharapkan dengan adanya bantuan ini membuat pengelola terus termotivasi sehingga tercipta kemandirian di Kampung Wisata ini sehingga pengelolaan bisa berjalan terus secara optimal. 


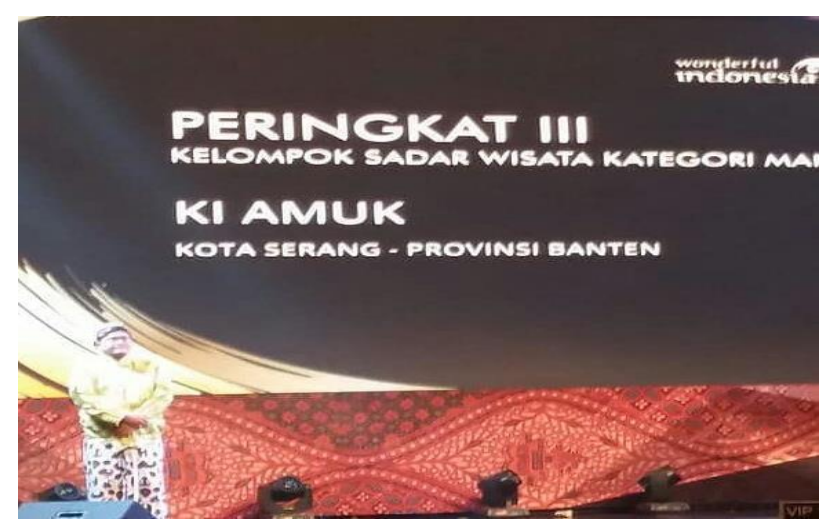

Gambar 3. Saat Pokdarwis Kiamuk menjadi juara 3 Kategori Mandiri, Ritzcalton Jakarta 2019

Sumber : Pokdarwis Kiamuk

\section{Simpulan dan Saran}

Berdasarkan data yang didapat terhadap pengelolaan pariwisata di Kampung Wisata Pancer menunjukkan bahwa kampung ini telah memiliki komponen yang disyaratkan sebagai sebuah destinasi pariwisata. Namun tetap membutuhkan pembenahan pada komponen amenities yaitu pengelolaan sampah dan pengadaan air bersih. Penyelenggaraan program Sapta Pesona melalui Pokdarwis belum mampu menemukan jalankeluar bagi pengelolaan sampah di Kampung Wisata Pancer. Sedangkan untuk keberagaman budaya, juga belum dapat dikembangkan secara berkesinambungan di kampung ini.

Meskipun secara ekonomi, sebagian masyarakat Kampung Pancer telah merasakan manfaat positif dengan adanya lapangan kerja baru serta penghasilan yang meningkat dari sector pariwisata, namun peningkatan ekonomi dari kegiatan wisata belum dirasakan merata. Sehingga dapat disimpulkan bahwa upaya pengembangan pariwisata di Kampung Wisata Pancer belum seluruhnya sesuai dengan konsep pembangunan pariwisata berkelanjutan. Diperlukan adanya dukungan serta pendampingan dari para stakeholder pariwisata terutama dari 
pemerintah agar tata kelola pariwisata di Kampung Wisata Pancer dapat lebih terencana dan berkelanjutan hingga dimasa yang akan datang.

\section{Daftar Pustaka}

Ardika, I. (2005). Pariwisata Bali: Membangun Pariwisata - Budaya dan Mengendalikan Budaya Pariwisata (pp. 20-33). P. B. Post.

Böcker, L., \& Meelen, T. (2017). Sharing for people, planet or profit? Analysing motivations for intended sharing economy participation. Environmental Innovation and Societal Transitions, 23, 28-39. https://doi.org/10.1016/j.eist.2016.09.004

Camisón, C. (2020). Competitiveness and Sustainability in Tourist Firms and Destinations. Sustainability, 12(6), 2388. https://doi.org/10.3390/su12062388

Cooper, C. et all. (2005). Tourism - Principles and Practice (Third Edit). Pearson Education.

Djou, J. A. G., Baiquni, M., Widodo, T., \& Fandeli, C. (2017). Symbolic participation in community-based tourism in Kelimutu National Park, Ende, East Nusa Tenggara. IOSR Journal of Business and Management, 19(01), 15-20. https://doi.org/10.9790/487x-1901071520

Elkington, J. (1994). Towards the Sustainable Corporation: Win-Win-Win Business Strategies for Sustainable Development. California Management Review, 36(2), 90-100. https://doi.org/10.2307/41165746

Emzir, M. (2012). Metodologi Penelitian Kualitatif Analisis data. Raja Grafindo.

Farmaki, A., \& Stergiou, D. P. (2019). Escaping loneliness Through Airbnb host-guest interactions. Tourism Management, 74, 331-333. https://doi.org/10.1016/j.tourman.2019.04.006

Goeldner, C. R., \& Ritchie, J. B. (2009). Tourism: Principles. Practices, Philosophies. 2.

KemenkeuRI. (2019). \#SadarAPBN. https://www.kemenkeu.go.id/sadarapbn

Lee, C. F., \& King, B. (2019). Determinants of attractiveness for a seniors-friendly destination: a hierarchical approach. Current Issues in Tourism, 22(1), 71-90. https://doi.org/10.1080/13683500.2016.1250725 
Mrsic, L., Surla, G., \& Balkovic, M. (2020). Smart Tourist Destination Management Using Demand Forecasting Techniques: Using Big Data for Destination Demand Forecasting as Part of a Destination Management System. In Handbook of Research on Smart Technology Models for Business and Industry (pp. 273-293). IGI Global.

Nirwandar, S. (2011). Pembangunan Sektor Pariwisata Di Era Otonomi Daerah. Ministry of Indonesian Tourism, 1-10.

Pan, S. Y., Gao, M., Kim, H., Shah, K. J., Pei, S. L., \& Chiang, P. C. (2018). Advances and challenges in sustainable tourism toward a green economy. In Science of the Total Environment (Vol. 635, pp. 452-469). Elsevier B.V. https://doi.org/10.1016/j.scitotenv.2018.04.134

Postma, A., Cavagnaro, E., \& Spruyt, E. (2017). Sustainable tourism 2040. Journal of Tourism Futures, 3(1), 13-22. https://doi.org/10.1108/JTF-10-2015-0046

Rahayu, S., Utami, Dewi, M. P., \& Kurnia Nur, Fitriana, M. (2015). Pengembangan Pariwisata Berbasis Masyarakat (Community Based Tourism) Di Kabupaten Kulon Progo Daerah Istimewa Yogyakarta.

Rakhman, C. U., Suganda, D., Dienaputra, R. D., \& Nirwandar, S. (2014). Community - Based Tourism Development Model in the District of Pangandaran. International Journal of Culture and History, 1(1), 34. https://doi.org/10.5296/ijch.v1i1.4970

Sahabudin, A., Rusdin, T., \& Hadian, M. (2020). Kegiatan Daur Ualang Sampah Gelas Plastik sebagai Wisata Edukasi di Kampung Wisata Pancer. In Potensi Wisata Jawa Barat (pp. 155-165). Unpad Press.

Tjandrasasmita, U., Ambary, H. M., \& Michrob, H. (1999). Mengenal Peninggalan Sejarah dan Purbakala Kota Banten Lama. In Banten Menuju Masa Depan (pp. 72-234). Yayasan Kiai Haji Wasid.

UNWTO. (2013). Sustainable Tourism for Development Guidebook - Enhancing capacities for Sustainable Tourism for development in developing countries. In Sustainable Tourism for Development Guidebook - Enhancing capacities for Sustainable Tourism for development in developing countries. World Tourism Organization (UNWTO). https://doi.org/10.18111/9789284415496

UNWTO Tourism Highlights: 2018 Edition I UNWTO. (2018). https://www.unwto.org/global/publication/unwto-tourism-highlights-2018edition 


\section{Profil Penulis}

Irwan adalah pelaku wisata yang sering terlibat didalam pengembangan pemberdayaan masyarakat melalui Community Based Tourism. Sebagai Founder $\mathcal{E}$ CEO WisataSekolah, Irwan memiliki pengalaman lebih dari 20 tahun dalam kegiatan wisata edukasi dan pembelajaran diluar kelas (Experiential Education). Kecintaannya terhadap pengembangan konsep wisata edukasi di Indonesia telah mengantarkannya sebagai peraih Top 3 Tourism Startup pada program inkubasi perusahaan rintisan Wonderful Startup Academy yang diadakan oleh Kementerian Pariwisata Republik Indonesia pada tahun 2019. Dipercaya sebagai Juri Nasional Lomba Desa Wisata Kementrian Desa \& PDTT pada tahun yang sama, Irwan saat ini mendirikan Outing.id - startup Educational \& Experiential Travel Platform dan melanjutkan pendidikannya di Sekolah Pasca Sarjana, Magister Pariwisata berkelanjutan UNPAD.

Dr. Drs. Rusdin, M.Si., (www.rusdintahir.com), sejak 1996 bekerja sebagai Dosen dan Peneliti di Departemen Administrasi Bisnis dan pengampu subjek Organisasi dan Manajemen, Strategi Sumber Daya Manusia, Pengukuran Kinerja dan Strategi Kompensasi, Perilaku Organisasi, Filsafat Ilmu Pengetahuan, dan Metodologi Penelitian di Sekolah Pascasarjana Program Studi Pariwisata Berkelanjutan, Master dan Program Studi Doktor. Program Pascasarjana Ilmu Administrasi Bisnis di Universitas Padjadjadjaran. Meraih Sarjana \& Pascasarjana: Administrasi Bisnis, Universitas Pendidikan Indonesia (1992); Gelar Master (2000) Gelar Doktor (2013) di Universitas Padjadjaran.

Dr. M. Liga Suryadana M.si., Lahir di Bandung, 4 Mei 1960, M. Liga Suryadana adalah seorang Lektor Kepala di Sekolah Tinggi Pariwisata Bandung (STPB). Pengalaman bekerja dibidang pariwisata sejak tahun 1985 menjadikannya sebagai salah seorang ahli dibidang tersebut. Berbagai macam penelitian serta karya ilmiah yang dimiliki membuat beliau dipercaya sebagai pengurus di beberapa organisasi profesi dan ilmiah. Saat ini beliau aktif mengajar sebagai dosen program sarjana, 
magister dan doctoral di Sekolah Tinggi Pariwisata Bandung, Sekolah Pasca Sarjana Unpad serta di beberapa perguruan tinggi lainnya di Indonesia.

Arfah Sahabudin, S.Kom. M.Par., lahir di Polmas (Polewali Mamasa) Sulawesi Barat 17 September 1972. Adalah seorang pelaku wisata (Pokdarwis Kiamuk, Kampung Wisata Pancer, Himpunan Pramuwisata Indonesia, Catering \& Jasa Boga, kerajinan daur ulang, aneka oleh-oleh khas Banten, dan Coffeeshop). Mendapatkan gelar S1 dari Universitas Gunadarma Depok jurusan Manajemen Informatika pada tahun 1995. Saat ini aktif sebagai pendamping Desa Wisata di Kota Serang setelah menyelesaikan studinya di Sekolah Pasca Sarjana, Program Studi Pariwisata Berkelanjutan UNPAD. 